\title{
In Vivo Evidence of Impaired Solute Transport by the Thick Ascending Limb in Potassium-depleted Rats
}

Hans U. Gutsche, Linda N. Peterson, and David Z. Levine Departments of Medicine, Pediatrics, and Physiology, University of Ottawa, Ottawa General Hospital, Ottawa, Ontario, Canada KIH $8 L 6$

bstract. The objective of this investigation was to determine if thick ascending limb (TAL) solute removal is impaired in potassium-depleted rats, in vivo. We estimated TAL $\mathrm{NaCl}$ concentration by measuring in situ conductivity of tubular fluid presented to the early distal site after stop-flow periods of 10-60 s, during which a proximal equilibrium solution remained in contact with the reabsorbing epithelium. This allowed us to calculate the rate constant of the decrease in tubular fluid $\mathrm{NaCl}$ concentration and to determine equilibrium values for control, potassium-depleted, and potassium-repleted rats. After $60 \mathrm{~s}$ of stop-flow, $\mathrm{NaCl}$ concentration of TAL fluid decreased to $18.3 \pm 2.73 \mathrm{mM}$ in control rats, while potassium-depleted rats had values almost twice as high (36.5 $\pm 2.97 \mathrm{mM}, P<0.01)$. The amount of $\mathrm{NaCl}$ remaining after $60 \mathrm{~s}$ of stop-flow in $\mathrm{K}$-depleted rats was highly correlated with the plasma $\mathrm{K}$ concentration. Calculated rates of $\mathrm{NaCl}$ efflux from the TAL appeared to be normal in K-depleted rats while the concentration of $\mathrm{NaCl}$ achieved at equilibrium was nearly twice that measured in control rats. Acute systemic administration of $\mathrm{KCl}$ by gavage or infusion in $\mathrm{K}$-depleted rats was associated with a decrease in $\mathrm{TAL} \mathrm{NaCl}$ concentration to

Part of this work has already appeared in abstract form (Kidney Int. 1983. 23:265a).

Dr. Peterson is a Scholar of the Medical Research Council of Canada. Drs. Peterson and Levine are recipients of Medical Research Council Grants' MA3836 and MA7745. This work was undertaken during Dr. Gutsche's sabbatical year. Dr. Gutsche's present address is 1 Medizinische Klinik, D-2300 Kiel 1, Federal Republic of Germany. Address reprint requests to Dr. Levine, Department of Medicine, Health Sciences Building, University of Ottawa, 451 Smyth Rd., Ottawa, Ontario, Canada KIH 8M5. 1983.

Received for publication 1 June 1983 and in revised form 6 December

J. Clin. Invest.

(c) The American Society for Clinical Investigation, Inc. 0021-9738/84/04/0908/09 \$1.00

Volume 73, April 1984, 908-916 normal values. Addition of $\mathrm{K}$ to the perfusate, however, did not repair the defect.

Our results can best be explained by assigning a special role to the peritubular $K$ concentration. We suggest that the defect in TAL solute removal in K-depletion can be rapidly reversed, because decreases in peritubular $\mathrm{K}$ concentration limit $\mathrm{Na}$ efflux across the peritubular membrane by decreasing the activity of the Na-K-ATPase pump. We recognize that factors such as regional renal blood flow, local angiotensin II levels, and products of the cyclo-oxygenase enzyme system may play a role.

\section{Introduction}

For decades it has been appreciated that potassium depletion is associated with an impairment in urine concentrating ability. Alterations in renal hemodynamics, medullary solute concentration, and antidiuretic hormone release have been postulated at one time or another to mediate this defect. Medullary blood flow, however, has not been shown to be increased (1) and hence could not affect a "washout" of medullary solute (2). Similarly, the concentrating defect has been shown to be independent of circulating levels of antidiuretic hormone $(3,4)$. In view of these and other findings, Eknoyan et al. (5) have postulated that a reduction in $\mathrm{Na}$ transport by the thick ascending limb (TAL) ${ }^{1}$ could explain the concentrating defect of K-depletion. The present investigations have been directed to an in vivo evaluation of this possibility in K-depleted rats. The newly developed stopflow conductivity probe technique of Gutsche et al. $(6,7)$ makes possible a reliable measure of solute concentration in TAL fluid as it is presented to the early distal micropuncture site. Using this method we have been able to clearly show $(a)$ that Kdepleted rats have a striking impairment in TAL solute removal,

1. Abbreviations used in this paper: $\mathrm{AA}$, atomic absorption; $\mathrm{BW}$, body weight; $\mathrm{C}_{\mathrm{Eq}}$, equilibrium $\mathrm{NaCl}$ concentration; $\mathrm{C}_{0}$, initial $\mathrm{NaCl}$ concentration during continuous perfusion of the loop for at least $15 \mathrm{~s} ; \mathrm{KW}$, kidney weight; $\mathrm{C}_{t}$, minimum $\mathrm{NaCl}$ concentration achieved following each stop-flow interval; $P_{t}$, percentage of perfusate concentration remaining at each time point; $\tau$, rate constant; SNK, Student-NewmanKeul; TAL, thick ascending limb. 
(b) that this impairment is correlated with the plasma $\mathrm{K}$ concentration in the K-depleted rats, and (c) that it is completely reversed when $\mathrm{K}$ stores are repleted.

\section{Methods}

\section{General}

Male Sprague-Dawley rats weighing 250-340 g from our colony at the University of Ottawa were divided into four experimental groups. In group 1, normal control rats consumed standard rat chow (Ralston Purina Co., St. Louis, MO), drank tap water, and were infused with $150 \mathrm{mM} \mathrm{NaCl}, 1 \%$ body weight $(\mathrm{BW}) / \mathrm{h}(n=7)$. In group 2, $\mathrm{K}$-depleted rats consumed a $\mathrm{K}$-free diet, ${ }^{2}$ drank distilled water for $11-16 \mathrm{~d}$, and were infused with $150 \mathrm{mM} \mathrm{NaCl}, 1 \% \mathrm{BW} / \mathrm{h}(n=7)$. In group 3, Krepleted rats consumed the $\mathrm{K}$-free diet as in group 2 for $11-16 \mathrm{~d}$ and then received an oral $\mathrm{KCl}$ load by gavage of $1 \mathrm{ml} / 100 \mathrm{~g} \mathrm{BW}$ of a 450$\mathrm{mM}$ solution. Preparation of the animals for micropuncture was initiated $\sim 2 \mathrm{~h}$ after $\mathrm{KCl}$ was given and they were infused with $150 \mathrm{mM} \mathrm{NaCl}$, $1 \% \mathrm{BW} / \mathrm{h}(n=7)$. In group $4, \mathrm{~K}$-infused rats consumed the $\mathrm{K}$-free diet for $11-16 \mathrm{~d}$ and were infused with $150 \mathrm{mM} \mathrm{KCl}, 1 \% \mathrm{BW} / \mathrm{h}(n=3)$. Plasma $\mathrm{K}$ concentrations were measured before and during the infusion of $\mathrm{KCl}$. Micropuncture commenced $30 \mathrm{~min}$ after the $\mathrm{KCl}$ infusion was initiated.

Animals were anesthetized with an intraperitoneal injection of Inactin (Byk Gulden Konstantz, Federal Republic of Germany) at a dose of $100 \mathrm{mg} / \mathrm{kg}$ BW, prepared for micropuncture as previously described (8). Approximately $50 \%$ of the K-depleted rats (group 2) were unsuitable for micropuncture experiments due to decreases in blood pressure below $95 \mathrm{mmHg}$. The majority of these rats had a plasma $\mathrm{K}<2.0 \mathrm{mM}$. Two or three 30-min urine collections with corresponding blood samples were taken during the course of the micropuncture experiment. At the end of clearance and micropuncture experiments the kidneys of all groups were examined histologically for the presence of medullary lesions characteristic of K-depletion $(9,10)$.

\section{Microperfusion-conductivity experiments}

Sodium chloride transport by the TAL was assessed by measuring the conductivity of tubular fluid emerging from the loop of Henle after different intervals of stop-flow in perfused nephrons. The micro stopflow method and the use of the conductivity probe have been described in detail in a previous paper (6) and have been further evaluated in the present investigation (see below). Briefly, randomly selected late proximal segments were perfused at $90 \mathrm{nl} / \mathrm{min}$ with a modified Klotz-Munich microperfusion pump using glass micropipettes with outer diameters of 8-10 $\mu \mathrm{m}$. Two perfusion solutions were used. Solution 1 (zero K): (a proximal equilibrium solution) $110 \mathrm{mM} \mathrm{NaCl}$ and $80 \mathrm{mM}$ mannitol, or solution $2(5 \mathrm{mM} \mathrm{K}): 5 \mathrm{mM} \mathrm{K}, 105 \mathrm{mM} \mathrm{Na}, 110 \mathrm{mM} \mathrm{Cl}$, and 80 $\mathrm{mM}$ mannitol. Both perfusates were lightly colored with $0.1 \%$ lissamine green dye. A solid paraffin block was placed into the preterminal proximal segment and the loop was perfused from the terminal proximal segment. Representative data from a control animal collected from a single nephron are shown in Fig. 1. The conductivity probe calibration in distilled water and in $155 \mathrm{mM} \mathrm{NaCl}$ bathing the kidney is performed at the beginning

2. The composition of the potassium-free diet in grams per kilogram was: $\mathrm{Na}_{2} \mathrm{CO}_{3} 0.406, \mathrm{NaCl} 0.824,4 \mathrm{MgCO}_{3} \cdot \mathrm{Mg}\left(\mathrm{OH}_{2}\right) \cdot \mathrm{H}_{2} \mathrm{O} 1.594,600$ $\mathrm{ml}$ of distilled water, and 997.2 Basal diet (TD 78093, TEKLAD, Madison, WI). and the end of each set of recordings from a single nephron. Fluid is drawn into the probe at a constant rate of $20 \mathrm{nl} / \mathrm{min}$ when measurements are being made. Initially the reading of the probe is high corresponding to the bathing medium. Upon entering the early distal tubule of the perfused nephron, the reading falls to a value of $\sim 90 \mathrm{mM} \mathrm{NaCl}$. Fluid can be made stationary in the loop by turning off the microperfusion and aspiration pumps positioned at $A$ and $B$, respectively, in Fig. 1, for predetermined periods of time. At the end of these intervals, the pumps are reactivated, the fluid is rapidly propelled distally and aspirated by the conductivity probe. Loops were perfused for time intervals of 15 to $30 \mathrm{~s}$ at a rate of $90 \mathrm{nl} / \mathrm{min}$ before the interruption of flow. Equilibration times of $10,20,30,45$, or $60 \mathrm{~s}$ were chosen at random. Usually all five equilibration times were studied in each nephron with duplicates of each time interval taken whenever possible. As Fig. 1 shows, conductivity is always reduced transiently after flow is resumed, but within $5 \mathrm{~s}$ after reestablishing flow within the loop of Henle tubular fluid conductivity returns to the value measured before the stop-flow interval. These rapid changes in tubular fluid conductivity were recorded continuously by a Linseis, series LS-64 recorder (Linseis Inc., Princeton Junction, NJ). The response time of this system, including the microprobe, detector (described below) and the recorder was $0.4 \pm 0.07 \mathrm{~s}$ in ten separate determinations. The response time is more rapid than the 3-5-s time course of the transient changes in tubular fluid conductivity. The initial $\mathrm{NaCl}$ concentration during continuous perfusion of the loop for at least $15 \mathrm{~s}\left(\mathrm{C}_{0}\right)$, and the minimum $\mathrm{NaCl}$ concentration achieved following each stop-flow interval $\left(C_{2}\right)$ were recorded for each nephron system.

Microperfusion-conductivity experiments were performed in groups $1-4$, using solution 1 (zero $\mathrm{K}$ ) for loop perfusion. In two additional $\mathrm{K}$ depleted rats (group 2), loops were perfused with the $5 \mathrm{mM} \mathrm{KCl}$ solution (solution 2).

In a separate study, loops of Henle in three control and three Kdepleted rats were perfused at $90 \mathrm{nl} / \mathrm{min}$ with solution 1 or solution 2 to measure steady state $\mathrm{K}$ concentration in fluid collected from the early

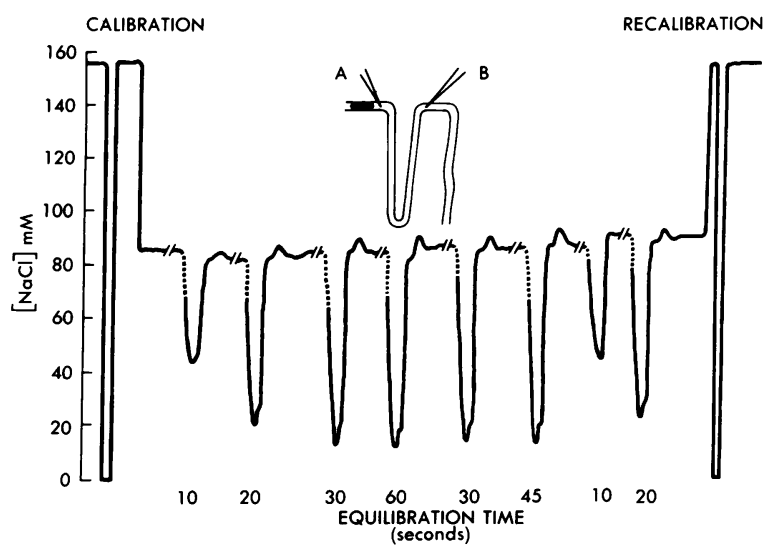

Figure 1. Fig. 1 is representative data collected from a single nephron in a control animal redrawn from actual recordings during a micro stop-flow experiment. The broken lines depict stop-intervals during which measurements were not made. Calibration of the conductivity probe in the medium bathing the kidney is performed at the beginning and at the end of each set of recordings. The figure shows the steady state $\mathrm{C}_{0}$ measured during continuous perfusion of the loop at $90 \mathrm{nl} / \mathrm{min}$, and the rapid transient decrease in tubular fluid $[\mathrm{NaCl}]$ after each randomly chosen stop-flow interval. 
distal site by graphite furnace atomic absorption spectrophotometry (Instrumentation Laboratories, Lexington, MA, model 951/655).

\section{Factors influencing the estimation of $\mathrm{NaCl}$ concentration by the conductivity probe}

General. Sodium chloride concentration was estimated in vivo by measuring the conductivity of tubular fluid using microconductivity probes, the construction of which has been described in a previous paper (6). Briefly, the conductivity probe is a platinum-coated micropuncture pipette with an outer diameter of 5-7 $\mu \mathrm{m}$ into which a platinum wire is inserted. The probe is mounted into the dome of a Hampel microperfusion pump (Wolfgang Hampel, Frankfurt, Federal Republic of Germany) modified to accept the wires coming from the conductivity detector (Dr. H Knauer, Bad Homberg, Federal Republic of Germany). A constant AC voltage generated by the detector is measured between the outer platinum coating of the micropipette and a platinum wire within the micropipette. The method permits the determination of different concentrations of pure salt solutions, but cannot discriminate between salt solutions of different compositions. Since the method estimates $[\mathrm{NaCl}]$ by assessing a different property of the solution, namely its electrical resistance, it is important to know what may influence the conductivity of tubular fluid and consequently the reliability of this estimate. Temperature, concentration effects, lissamine green dye, urea, mannitol, and the presence of ions other than $\mathrm{Na}$ and $\mathrm{Cl}$ in the perfused fluid were evaluated as possible sources of significant error.

Temperature and concentration effects. The conductance of an ion is increased by temperature (11). A systematic overestimate of $\mathrm{NaCl}$ concentration could result if the medium bathing the kidney was cooler than the kidney itself. For example, if the probe is calibrated in the surface fluid at $35^{\circ} \mathrm{C}$, and then aspirates fluid in the nephron at $37^{\circ} \mathrm{C}$, a $3 \%$ increase in the $[\mathrm{NaCl}]$ would occur (11). The percent change is greater as the temperature difference increases, but is constant for sodium concentrations ranging from 10 to $200 \mathrm{mM}$ (11). In our study, the rat, kidney cup, and fluid bathing the kidney were heated in parallel to $37^{\circ} \mathrm{C}$ by a constant temperature water bath.

The conductance of an ion is affected by the concentration of the ion in solution. For example, the molecular conductance of $\mathrm{NaCl}$ in a $20 \mathrm{mM}$ solution is $12 \%$ higher than that measured in a $155 \mathrm{mM}$ solution (11). Since the conductivity probes were calibrated in $155 \mathrm{mM} \mathrm{NaCl}$, which bathed the kidney, but sampled fluid emerging from the TAL with concentrations of $\sim 20 \mathrm{mM}$, an overestimate of tubular fluid sodium concentration was expected. The overestimate of $\mathrm{NaCl}$ concentration increases as $\mathrm{NaCl}$ concentration decreases (percentage of increase $=-0.14(\mathrm{NaCl} \mathrm{mM})+15.3, r=0.97$, calculated as in reference 11$)$. The maximum error that could be introduced by this factor is $\sim 16 \%$ when measuring a $\mathrm{NaCl}$ concentration of $10 \mathrm{mM}$.

Effects of mannitol, urea, and lissamine green dye. To determine the effects of lissamine green dye, mannitol, and urea on the [ $\mathrm{NaCl}]$, the following in vitro tests were performed. After calibration of the microprobe in a standard solution of $155 \mathrm{mM} \mathrm{NaCl}$, sodium concentration of 11 standard solutions was measured, ranging from 0 to 155 $\mathrm{mM} \mathrm{NaCl}(0,9.1,17.2,31.0,38.8,51.7,77.5,103.3,116.3,124.0$, and $155 \mathrm{mM} \mathrm{NaCl}$ ). The values estimated by the conductivity probe did not differ significantly from those obtained by flame photometry (Instrumentation Laboratories, model 343). In addition, the coefficient of variation for the reading of any standard solution by the probe did not exceed $1.6 \%$. The accuracy of the microprobe was similar whether fluid entered the probe at rates of 4 or $20 \mathrm{nl} / \mathrm{min}$. The ability of the probe to estimate $[\mathrm{NaCl}]$ was also assessed in the presence of $80 \mathrm{mM}$ mannitol and $120-220 \mathrm{mM}$ urea. There was no effect of mannitol on the per- formance of the probe in $\mathrm{NaCl}$ concentrations $₹ 103 \mathrm{mM}$. For a $\mathrm{Na}$ concentration of $110 \mathrm{mM}$, there was an average decrease in the estimated $\mathrm{Na}$ concentration of $\sim 4 \%$. There was no significant effect of urea at the concentrations tested on the ability of the probe to estimate $[\mathrm{NaCl}]$ in the test solutions described above. The $0.1 \%$ lissamine green dye used to color the perfusate contributed $4 \mathrm{mM}$ of $\mathrm{Na}$ to the solutions, but did not affect the accuracy of the conductivity probe.

In vivo comparison with atomic absorption $(A A)$ spectroscopy. From the results of loop perfusion studies performed by Morgan and Berliner (12), de Rouffignac and Morel (13), Levine et al. $(14,15)$, and Jamison et al. (16) we can estimate the concentrations of $\mathrm{K}^{+}, \mathrm{Ca}^{++}$and $\mathrm{HCO}_{3}^{-}$ in the early distal fluid and hence in the diluting segment to be 3.6, 0.5, and $2.2 \mathrm{mM}$, respectively, when the loop is perfused at a rate of $90 \mathrm{nl} /$ min with a $110 \mathrm{mM} \mathrm{NaCl}$ solution. To the extent that these ions enter the perfused loop, the estimate of $\mathrm{Na}$ concentration by the probe will differ from the actual concentration of $\mathrm{Na}$ in tubular fluid. The ability of the conductivity microprobe to estimate $\mathrm{NaCl}$ concentration in fluid emerging from the TAL in a perfused nephron was compared with the sodium concentration measured by graphite furnace atomic absorption spectrophotometry in a sample collected from the same early distal site. In this study, randomly chosen loops of Henle were perfused from a late proximal site at $90 \mathrm{nl} / \mathrm{min}$, while fluid in the upstream proximal segment was interrupted by the introduction of a wax block. The conductivity probe was inserted into the first accessible distal segment and a stable reading was obtained. While the perfusion continued, the probe was withdrawn and a collection pipette was inserted in its place to sample the tubular fluid. The collection pipette was withdrawn and the conductivity probe was repositioned in the same segment without interruption in the perfusion of the loop. A stable conductivity reading was again obtained. Collections of tubular fluid for AA analysis were bracketed by readings of the conductivity probe during continuous perfusion in the same nephron. To obtain a series of comparisons between the probe and $\mathrm{AA}$ analysis, four perfusate solutions were used containing the following sodium chloride concentrations: $110,50,20$, and $7 \mathrm{mM}$; each contained $80 \mathrm{mM}$ mannitol, $0.1 \%$ lissamine green, and urea to adjust the osmolarity to $300 \mathrm{mosmol} / \mathrm{kg}$. Sodium concentration estimated by the conductivity probe was highly correlated with the measurement of [Na] by AA ( $r=0.986, P<0.001$, probe estimate $=0.885$ (AA) $+11.14)$ in 25 samples taken from four animals. The ratio of the conductivity probe estimate to the AA measurement in each of the 25 samples was $1.12 \pm 0.031$ for $\mathrm{Na}$ concentrations ranging from 28 to $112 \mathrm{mM}$.

These data indicate that the probe estimate of $\mathrm{Na}$ concentration in tubular fluid will be higher than the existing concentration when $\mathrm{NaCl}$ concentration is $<80 \mathrm{mM}$. The lack of perfect agreement between the probe and $\mathrm{AA}$ analysis for low $\mathrm{NaCl}$ concentrations can probably be attributed to the added effects of the difference in $\mathrm{Na}$ conductance at low and high $\mathrm{Na}$ concentrations (discussed above), and to the presence of other ions that have entered the loop. This in vivo comparison between the probe and AA encompasses all the factors that affect the accuracy of the conductivity measurements, namely temperature, dilution, nonelectrolytes, and entrance of other ions into the perfused loops. We expect that the contribution of these factors would be similar in the four groups of animals studied. It is clear, however, from the equation given above that the error in determining the concentration of a $20 \mathrm{mM}$ $\mathrm{NaCl}$ solution by the probe is greater than the error in determining the concentration of a $40 \mathrm{mM} \mathrm{NaCl}$ solution. The most important finding of the present study is that $\mathrm{K}$-depleted rats are unable to reduce the $\mathrm{NaCl}$ concentration to the same minimal values measured in controls. The difference after $60 \mathrm{~s}$ of stop-flow is $\sim 18 \mathrm{mM}(36.5 \pm 2.97 \mathrm{vs}$. 
$18.3 \pm 2.73 \mathrm{mM}$ ). If we calculate the corresponding $\mathrm{NaCl}$ concentrations that would be expected by AA analysis (equation given above), despite a decrease in the absolute values of $\mathrm{NaCl}$ concentration, a similar difference remains $(19 \mathrm{mM})$. Therefore, errors intrinsic to the estimation of $\mathrm{NaCl}$ concentration by measurement of tubular fluid conductivity cannot account for the nearly twofold increase in $\mathrm{NaCl}$ concentration measured in K-depleted rats compared with control animals (see Results).

\section{Analysis of urine and blood}

Urine volume was obtained by weighing; $\mathrm{Na}$ and $\mathrm{K}$ in urine and plasma were measured by flame photometry. Inulin concentrations were calculated by counting radioactivity in a liquid scintillation counter. Glomerular filtration rate (GFR) and electrolyte excretions were calculated in a standard way.

\section{Calculations and statistical analysis}

Assuming a two-compartment pump-leak system underlying the $\mathrm{NaCl}$ transport in the diluting segment, the following equation describes the time course of the decrease in $\mathrm{NaCl}$ concentration with increasing equilibration time: $C_{t}=\left(C_{0}-C_{E q}\right) e^{-\tau \cdot t}+C_{E q}$ (7). Using this equation, the conductivity data obtained in each individual nephron were used to calculate the rate constant $(\tau)$, and the equilibrium $\mathrm{NaCl}$ concentration, $\mathrm{C}_{\mathrm{Eq}}$, by approximating both parameters in an iterative least-squares regression analysis (7). The percentage of perfusate concentration remaining at each time point $\left(\mathrm{P}_{\mathbf{t}}\right)$ was calculated by dividing the $\mathrm{NaCl}$ concentration of tubular fluid measured after each stop-flow interval by the initial $\mathrm{NaCl}$ concentration during continuous perfusion $\left(\mathrm{C}_{0}\right)$ for each nephron $\left(C_{t} / C_{0} \times 100\right)$. The data obtained in each group are expressed as mean $\pm \mathrm{SEM}$. Differences between groups were assessed by one-way analysis of variance and the Student-Newman-Keul (SNK) multiple comparison test, and were considered significant if the value of $P$ was $<0.05$.

\section{Results}

As illustrated in Fig. 2, potassium-depleted rats had a lower plasma $\mathrm{K}$ concentration $(2.3 \pm 0.16 \mathrm{mM})$ and excreted $95 \%$ less $\mathrm{K}$ than controls. GFR was significantly reduced in the $\mathrm{K}$-depleted rats $\left(0.64 \pm 0.041\right.$ vs. $0.90 \pm 0.06 \mathrm{ml} / \mathrm{min}$ per $\mathrm{g}$ kidney weight ${ }^{-1}$

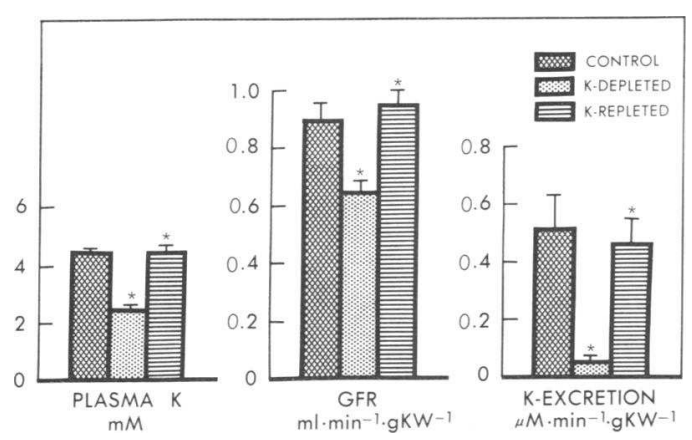

Figure 2. The effect of dietary K-depletion (14 d) and acute administration of $2.5 \mathrm{mM} \mathrm{KCl}$ by gavage on plasma [K], GFR, and K-excretion in control, K-depleted, and K-repleted rats. Results are expressed as means \pm SEM. * indicates significant difference at the level of $P$ $<0.01$ compared with the value immediately on the left.
Table I. Estimated TAL NaCl Concentration after Various Stop-Flow Intervals

\begin{tabular}{llllll}
\hline & $C_{0}$ & $C_{10}$ & $C_{30}$ & $C_{45}$ & $C_{60}$ \\
\hline Control & 93.2 & 49.3 & 23.4 & 20.1 & 18.3 \\
& \pm 2.96 & \pm 3.62 & \pm 1.91 & \pm 2.47 & \pm 2.73 \\
& $(15)$ & $(18)$ & $(18)$ & $(14)$ & $(10)$ \\
K-depleted & 99.2 & $64.1^{*}$ & $39.9^{*}$ & $33.6^{*}$ & $36.5^{*}$ \\
& \pm 2.00 & \pm 1.60 & \pm 2.64 & \pm 2.70 & \pm 2.97 \\
& $(20)$ & $(20)$ & $(20)$ & $(19)$ & $(17)$ \\
K-repleted & $84.9 \ddagger \S$ & $37.8^{*} \S$ & $16.0 \S$ & $13.9 \S$ & $10.7 \S$ \\
& \pm 2.06 & \pm 1.34 & \pm 1.08 & \pm 1.46 & \pm 1.31 \\
& $(18)$ & $(19)$ & $(18)$ & $(16)$ & $(14)$ \\
K-infused & $87.8 \S$ & $38.8^{*} \S$ & $15.3 \S$ & $14.7 \S$ & $11.9 \S$ \\
& \pm 1.64 & \pm 2.17 & \pm 2.15 & \pm 1.62 & \pm 1.56 \\
& $(13)$ & $(19)$ & $(14)$ & $(15)$ & $(12)$ \\
& & & & & \\
\hline
\end{tabular}

Steady state $[\mathrm{NaCl}]$ in millimolar of fluid emerging from loops of Henle perfused at $90 \mathrm{nl} / \mathrm{min}$ with a proximal equilibrium solution, $\mathrm{C}_{0}$, and concentrations measured after 10,30, 45, and $60 \mathrm{~s}$ of stopflow. Results are means \pm SEM. Values in parentheses are numbers of measurements. $P$ values are from the SNK multiple comparison test. * $P<0.01$ compared with control.

$\ddagger P<0.05$ compared with control.

$\S P<0.01$ compared with $\mathrm{K}$-depleted.

(KW), $P<0.01$ ). Acute replacement of $2.5 \mathrm{mM}$ of $\mathrm{K}$ by gavage increased plasma $K$ concentration and urinary $K$ excretion to normal values in K-repleted rats (Fig. 2). In addition to correcting plasma $\mathrm{K}$ and urinary $\mathrm{K}$ excretion in the $\mathrm{K}$-repleted group, the acute administration of $\mathrm{KCl}$ also returned GFR to normal values $\left(0.95 \pm 0.061\right.$, group 3 , vs. $0.90 \pm 0.062 \mathrm{ml} / \mathrm{min}$ per $\mathrm{g} \mathrm{KW}^{-1}$, group 1). The K-depleted rats that received the i.v. infusion of $\mathrm{KCl}$ during the experiment (group 4) had a plasma $\mathrm{K}$ of $2.1 \pm 0.06$ $\mathrm{mM}$ before infusion that increased to $3.2 \pm 0.14 \mathrm{mM}$ during the infusion. GFR in these animals was initially low, and in contrast to group 3 animals (above) did not increase in response to the $\mathrm{K}$ infusion $(0.54 \pm 0.009 \mathrm{NaCl}$ infusion vs. $0.58 \pm 0.061 \mathrm{KCl}$ infusion, $\mathrm{ml} / \mathrm{min}$ per $\left.\mathrm{g} \mathrm{KW}^{-1}, P>0.4, n=4\right)$. In all $\mathrm{K}$-depleted animals (groups 2-4) we observed membrane-bound lysosomal structures in medullary cells typical of $\mathrm{K}$-depletion, as previously reported $(9,10)$. No lesions were detected in kidneys obtained from control rats (group 1).

The estimated $\mathrm{NaCl}$ concentration in fluid emerging from the loop of Henle during continuous perfusion $\left(\mathrm{C}_{0}\right)$ and the concentrations $\left(C_{t}\right)$ measured after stop-flow periods of 10,30 , 45, and $60 \mathrm{~s}$ are given in Table $I$ for the four experimental groups. Although all loops of Henle were perfused at $90 \mathrm{nl} / \mathrm{min}$ with $110 \mathrm{mM} \mathrm{NaCl}$, there were differences in $\mathrm{C}_{0}$ (Table I). After periods of stop-flow in $\mathrm{K}$-depleted rats, the concentration of $\mathrm{NaCl}$ in fluid emerging from the perfused loop of Henle did not decrease to the same extent as in control, K-repleted, or $\mathrm{K}$ - 
infused groups. For example, after $10 \mathrm{~s}$ of stop-flow, $\mathrm{NaCl}$ concentration decreased to $49.3 \pm 3.62 \mathrm{mM}$ in the control rats, compared with $64.1 \pm 1.60 \mathrm{mM}$ in the $\mathrm{K}$-depleted group. As the time of stop-flow was increased up to $60 \mathrm{~s}$, the resulting concentration of $36.5 \pm 3.97 \mathrm{mM}$ in the $\mathrm{K}$-depleted group was almost twice that measured in control rats $(18.3 \pm 2.73 \mathrm{mM}, P<0.01)$. Before interruption of flow and after the 10-s stop-flow interval, there were significantly lower $\mathrm{Na}$ concentrations in groups 3 and 4 compared with the control group. However, this difference was not apparent after the 30-, 45-, and 60-s time intervals.

The values of $C_{0}$ and $C_{1}$ in each nephron were used to calculate the equation of the line describing the change in tubular fluid concentration as a function of time (Methods). This analysis of the data, which takes into consideration the initial $\mathrm{NaCl}$ concentration present in fluid emerging from the loop during continuous perfusion, $\mathrm{C}_{0}$, and the minimum substrate concentration achieved by each nephron, $C_{t}$, allows calculation of the rate constant, $\tau$, and the equilibrium $\mathrm{NaCl}$ concentration, $\mathrm{C}_{\mathrm{Eq}}$. The calculated lines for the experimental groups are illustrated in Fig. 3, and the kinetic parameters are presented in Table II. The striking impairment in loop-diluting function in $\mathrm{K}$-depleted rats as measured by the $\mathrm{C}_{\mathrm{Eq}}$, and the similarity between the control and the two $\mathrm{K}$-repaired groups is evident. The rate of decline of tubular fluid concentration as measured by the $\tau$ was similar in the four groups (Table II); the $\mathrm{C}_{\mathrm{Eq}}$ was significantly higher in the $\mathrm{K}$-depleted rats $(34.7 \pm 3.09 \mathrm{mM})$ compared with the control (13.8 $\pm 1.8 \mathrm{mM})$, K-repleted $(13.2 \pm 1.21 \mathrm{mM})$, or Kinfused $(12.9 \pm 1.02 \mathrm{mM})$ groups. Note that the calculated values of $\mathrm{C}_{\mathrm{Eq}}$ do not differ substantially from the TAL NaCl concentrations measured in these groups after the 60-s stop-flow period (Table I).

Since different concentrations of $\mathrm{Na}$ were present in fluid emerging from the loop of Henle before the onset of the stop-

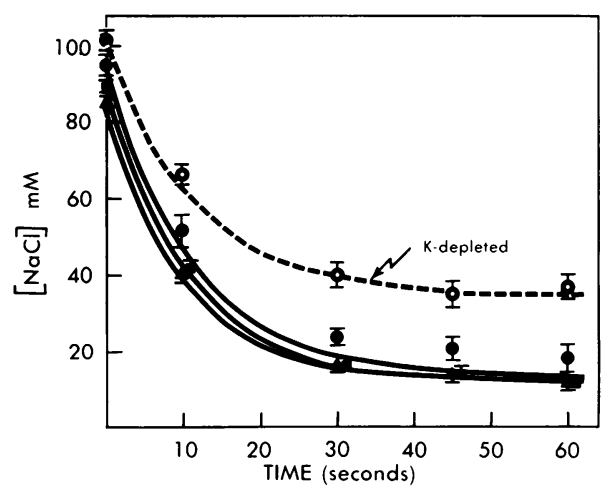

Figure 3. Time course of the continuous change in tubular fluid $[\mathrm{NaCl}]$ after intervals of stop-flow in $\mathrm{K}$-depleted, O, control, $\bullet, \mathrm{K}$-infused, $\square$, and $\mathrm{K}$-repleted, $\Delta$, rats. The lines were calculated from the equation: $C_{t}=\left(C_{0}-C_{E q}\right) e^{-r \cdot t}+C_{E q}$ (see Methods). Calculated values of the $\tau$ and the $C_{E q}$ were taken from Table II. Measured tubular fluid concentrations at steady state and after 10,30,45, and $60 \mathrm{~s}$ of stop-flow presented in Table I are also plotted on this figure.
Table II. Calculated TAL Transport Parameters: $\tau$ and $C_{E q}$

\begin{tabular}{lcc}
\hline & $\tau$ & $\mathrm{C}_{\mathrm{Eq}}$ \\
\hline \multirow{3}{*}{ Control } & $s^{-1}$ & $m M$ \\
& 0.096 & 13.8 \\
& \pm 0.0061 & \pm 1.8 \\
K-depleted & $(16)$ & $(16)$ \\
& 0.087 & $34.7 *$ \\
& \pm 0.0049 & \pm 3.09 \\
K-repleted & $(20)$ & $(20)$ \\
& 0.101 & $13.2 \ddagger$ \\
& \pm 0.0046 & \pm 1.21 \\
K-infused & $(18)$ & $(18)$ \\
& 0.095 & $12.9 \ddagger$ \\
& \pm 0.0046 & \pm 1.02 \\
& $(13)$ & $(13)$ \\
\end{tabular}

Values of TAL $[\mathrm{NaCl}]$ at $\mathrm{C}_{0}$ and after $10,30,45$, and $60 \mathrm{~s}$ of stopflow in each nephron were used to calculate $\tau$ and $\mathrm{C}_{\mathrm{Eq}}$ from the equation: $C_{t}=\left(C_{0}-C_{E q}\right) e^{-r \cdot t}+C_{E q}$ by approximating both parameters in an iterative least-squares regression analysis. Results are expressed as mean $\pm \mathrm{SEM}$. Values in parentheses are numbers of measurements. $P$ values are from the SNK multiple comparison test. $* P<0.01$ compared with control.

$\ddagger P<0.01$ compared with $\mathrm{K}$-depleted.

flow period in the four groups studied, we further analyzed the data by dividing the $\mathrm{NaCl}$ concentration of tubular fluid measured after each stop-flow interval by the initial $\mathrm{NaCl}$ concentration $\left(C_{0}\right)$ within the loop for each nephron $\left(C_{t} / C_{0} \times 100\right)$ to obtain the percent of perfusate concentration remaining $\left(P_{t}\right)$. These values, presented in Table III, show that almost $50 \%$ of the substrate available is reabsorbed by the ascending limb within $10 \mathrm{~s}$ in control animals while only $35 \%$ is removed by this segment in K-depleted rats. This difference is evident at each of the stop-flow intervals. We also found a linear relation, illustrated in Fig. 4, between the plasma potassium concentration and the $P_{t}$ after the 60-s stop-flow interval in the K-depleted animals $\left(\mathrm{P}_{60}=-0.363\right.$ (plasma $\left.\mathrm{K}\right)+1.24, r=0.91, n=17$, $P<0.001$ ). In addition, plasma $\mathrm{K}$ concentration and the $\mathrm{NaCl}$ concentration measured after the 60-s stop-flow interval in K-depleted rats was highly correlated $(r=0.84, P<0.001$, $n=17$ ).

To determine if delivery of $\mathrm{K}$ to the luminal membrane of the TAL could influence the $C_{\mathrm{Eq}}$ values noted above, we compared the effects of perfusates containing $\mathrm{K}$ with $\mathrm{K}$-free solutions. Steady state $\mathrm{K}$ concentration in fluid emerging from loops of Henle perfused at $90 \mathrm{nl} / \mathrm{min}$ with solution 1 (zero K) was measured in K-depleted and control rats. Steady state K concentration was also measured in groups 1 and 2 (Table IV) when loops were perfused with solution $2(5 \mathrm{mM} \mathrm{K})$. In these experiments, estimates of net secretion or reabsorption of $\mathrm{K}$ by 
Table III. Percentage of Initial [ $\mathrm{NaCl}]$ Present in TAL Fluid after Various Stop-Flow Intervals

\begin{tabular}{lllll}
\hline & $P_{10}$ & $P_{30}$ & $P_{45}$ & $P_{60}$ \\
\hline Control & 52.3 & 24.5 & 24.7 & 18.9 \\
& \pm 3.27 & \pm 1.69 & \pm 2.63 & \pm 2.45 \\
& $(17)$ & $(18)$ & $(14)$ & $(12)$ \\
K-depleted & $65.1^{*}$ & $39.8^{*}$ & $34.4^{*}$ & $37.2^{*}$ \\
& \pm 1.69 & \pm 2.82 & \pm 2.79 & \pm 3.12 \\
& $(20)$ & $(20)$ & $(19)$ & $(17)$ \\
K-repleted & $44.4 \ddagger \S$ & $19.0 \ddagger$ & $17.0 \ddagger$ & $12.0 \ddagger$ \\
& \pm 1.79 & \pm 1.25 & \pm 1.96 & \pm 1.78 \\
& $(19)$ & $(18)$ & $(16)$ & $(14)$ \\
K-infused & $43.5 \ddagger \S$ & $17.7 \ddagger$ & $16.3 \ddagger$ & $13.4 \ddagger$ \\
& \pm 2.30 & \pm 2.55 & \pm 1.67 & \pm 1.65 \\
& $(19)$ & $(14)$ & $(15)$ & $(12)$
\end{tabular}

Percentage of steady state $\mathrm{NaCl}$ concentration $\left(\mathrm{C}_{0}\right)$, in fluid emerging from perfused loops of Henle after stop-flow intervals of 10, 30, 45, and $60 \mathrm{~s}$. Results are expressed as mean \pm SEM. Values in parentheses are numbers of measurements. $P$ values are from the SNK multiple comparison test.

* $P<0.01$ compared with control.

$\ddagger P<0.01$ compared with $\mathrm{K}$-depleted.

$\S P<0.05$ compared with control.

the loop were calculated as: $[\mathrm{K}]_{\text {steady state }} \times$ perfusion rate. As shown in Table IV, $\mathrm{K}$ concentration in fluid emerging from loops of Henle was reduced in $\mathrm{K}$-depleted rats compared with controls when loops were perfused with zero $\mathrm{K}(1.3 \pm 0.06 \mathrm{mM}$ vs. $1.9 \pm 0.14 \mathrm{mM}, P<0.01)$. The net rate at which $\mathrm{K}$ entered loops perfused with zero $K$ in the $K$-depleted rats was $\sim 135$ $\mathrm{pM} / \mathrm{min}$, a value less than that measured in control rats (170 $\mathrm{pM} / \mathrm{min}$ ). When loops were perfused with the $5 \mathrm{mM} \mathrm{K}$ solution, reabsorption rather than secretion of $\mathrm{K}$ was observed in both groups of animals. Despite the high net rate of $\mathrm{K}$ reabsorption in K-depleted rats, $\sim 230 \mathrm{pM} / \mathrm{min}$ (a value which exceeded that measured in loops of Henle perfused with $5 \mathrm{mM} \mathrm{K}$ in control

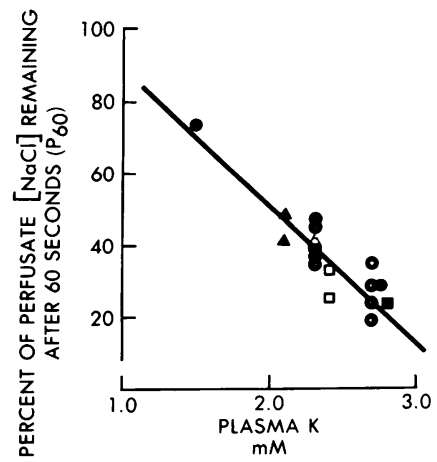

Figure 4. The relation between plasma $\mathrm{K}$ concentration in $\mathrm{K}$ depleted rats and the percent $\left(P_{t}\right)$ of the steady state $\mathrm{NaCl}$ concentration $\left(C_{60} / C_{0}\right)$ remaining after the 60-s stop-flow interval $(r=0.91, P<0.001, n$ $=17$ ). Symbols represent individual measurements in different animals.
Table IV. Steady State Potassium Concentration

\begin{tabular}{rll}
\hline & \multicolumn{2}{c}{ Collected fluid $[\mathrm{K}] \mathrm{mM}$} \\
\cline { 2 - 3 } & Control rats & \multicolumn{1}{c}{ K-depleted rats } \\
\hline Perfusate & & \\
$0 \mathrm{mM}$ & $1.9 \pm 0.14$ & $1.3 \pm 0.05^{*}$ \\
& $(8)$ & $(16)$ \\
$5 \mathrm{mM}$ & $3.3 \pm 0.17 \ddagger$ & $2.4 \pm 0.06^{*} \S \ddagger$ \\
& $(12)$ & $(12)$ \\
\hline
\end{tabular}

Potassium concentration in collected fluid emerging from loops of Henle perfused with zero $\mathrm{K}(110 \mathrm{mM} \mathrm{NaCl})$ or $5 \mathrm{~K}(105 \mathrm{mM} \mathrm{NaCl}$, $5 \mathrm{mM} \mathrm{KCl}$ ) at $90 \mathrm{nl} / \mathrm{min}$. Results are expressed as mean \pm SEM. Values in parentheses are numbers of measurements. $P$ values are from the SNK multiple comparison test.

* $P<0.01$ vs. control same perfusate $[\mathrm{K}]$.

$\ddagger P<0.01$ vs. zero $\mathrm{K}$ perfusate same diet.

$\S P<0.05$ vs. control zero $\mathrm{K}$ perfusate.

rats, $150 \mathrm{pM} / \mathrm{min}$ ), the concentration of $\mathrm{K}$ emerging from loops perfused with $5 \mathrm{mM} \mathrm{K}$ was clearly increased compared with values measured during perfusion with zero $\mathrm{K}(2.4 \pm 0.06 \mathrm{mM}$, $5 \mathrm{~K}$ vs. $1.3 \pm 0.05 \mathrm{mM}$, zero $\mathrm{K}, P<0.01$, Table IV). In addition, steady state $\mathrm{K}$ concentration measured during perfusion with $5 \mathrm{mM} \mathrm{K}$ in K-depleted rats exceeded the steady state concentration measured in control rats perfused with zero $\mathrm{K}(2.4 \pm 0.06$ K-depleted, $5 \mathrm{mM} \mathrm{K}$ vs. $1.9 \pm 0.14$ control, zero $\mathrm{K}, P<0.05$, Table IV).

The effect of perfusing the loop of Henle in the $\mathrm{K}$-depleted rat with the $5 \mathrm{mM} \mathrm{K}$ perfusate (solution 2) on $\mathrm{NaCl}$ transport by the TAL is shown on Table V. Micropuncture data collected from five nephrons in two $\mathrm{K}$-depleted rats (plasma $\mathrm{K}=2.2 \pm 0.12$

Table V. Loop Transport after Perfusion with $5 \mathrm{mM} \mathrm{K}$ in $K$-depleted Rats

\begin{tabular}{lcccc}
\hline $\mathrm{C}_{0}$ & $\mathrm{C}_{10}$ & $\mathrm{C}_{30}$ & $\mathrm{C}_{45}$ & $\mathrm{C}_{60}$ \\
\hline 105.4 & 69.4 & 46.8 & 44.1 & 42.7 \\
\pm 2.26 & \pm 3.70 & \pm 3.46 & \pm 4.45 & \pm 4.20 \\
& & & & \\
$\mathrm{P}_{0} \mathrm{~s}$ & $\mathrm{P}_{10} \mathrm{~s}$ & $\mathrm{P}_{30} \mathrm{~S}$ & $\mathrm{P}_{45} \mathrm{~s}$ & $\mathrm{P}_{60} \mathrm{~S}$ \\
100 & 65.8 & 44.5 & 41.9 & 40.3 \\
& \pm 2.74 & \pm 3.31 & \pm 4.21 & \pm 4.20 \\
\hline
\end{tabular}

Measurements of steady state $\mathrm{NaCl}$ concentration $\left(\mathrm{C}_{0}\right), \mathrm{NaCl}$ concentration $\left(C_{t}\right)$, and percent $\left(P_{t}\right)$ of the steady state $\mathrm{NaCl}$ concentration remaining after $10,30,45$, and $60 \mathrm{~s}$ of stop-flow in fluid emerging from loops of Henle in K-depleted rats perfused with $5 \mathrm{~K}(105 \mathrm{mM}$ $\mathrm{NaCl}$ and $5 \mathrm{mM} \mathrm{KCl}$ ) at $90 \mathrm{nl} / \mathrm{min}$. Results are expressed as mean \pm SEM and were obtained from five nephrons in two $\mathrm{K}$-depleted rats. 
$\mathrm{mM}$ ) show that the ability of the TAL to transport $\mathrm{NaCl}$ is still impaired, even when $\mathrm{KCl}(5 \mathrm{mM})$ perfuses the segment. The minimum concentrations reached following each stop-flow interval, the percent of perfusate concentration remaining (Table V), the transport parameters, $\tau=0.086 \pm 0.0053$, and $\mathrm{C}_{\mathrm{Eq}}=42.3 \pm 4.32 \mathrm{mM}$, are similar to those measured in other $\mathrm{K}$-depleted rats (Tables I-III) in which the loops were perfused with the zero $\mathrm{K}$ solution.

\section{Discussion}

The present studies were undertaken to assess, in vivo, TAL solute transport in K-depleted rats. Since the TAL is not accessible to surface micropuncture, the microstop-flow technique of Gutsche et al. $(6,7)$ made possible measurements of tubular fluid conductivity of TAL fluid reaching the early distal micropuncture site. This approach enabled us to demonstrate unequivocally that TAL solute reabsorption is defective in K-depleted rats, that the severity of the defect is correlated with the degree of decrease in plasma $\mathrm{K}$ concentration, and finally, that the defect is rapidly reversed with acute potassium administration.

As already detailed in Methods, we have paid particular attention to the validity of our conductivity probe measurements. Special studies were undertaken to exclude covert influences of lissamine green, urea, and mannitol on sodium estimations by the conductivity probe in a range from 0 to $110 \mathrm{mM}$. Further, we have confirmed that dilution and temperature effects could not have had a significant influence on our results. Most importantly, a separate series of in vivo experiments were undertaken wherein conductivity probe estimates of $\mathrm{NaCl}$ concentration were directly compared with chemical sodium analysis by the graphite furnace AA method in the same nephron. These comparisons indicate that there is an excellent correspondence between probe and chemical sodium analyses in vivo, and that errors intrinsic to the conductivity measurements cannot begin to account for the almost twofold difference in the equilibrium TAL $\mathrm{NaCl}$ concentrations associated with $\mathrm{K}$-depleted rats when compared with normal or K-repleted animals.

We have reported that the transient decrease in $\mathrm{NaCl}$ concentration of ascending limb fluid after periods of stop-flow as brief as $10 \mathrm{~s}$ is less in $\mathrm{K}$-depleted rats and that the difference persists for $60 \mathrm{~s}$ whether or not correction is made for the variations in solute presentation to the loop. Analysis of the change in tubular fluid $\mathrm{NaCl}$ concentration with respect to time shows that the rate of decrease of $[\mathrm{NaCl}]$ is not slower in $\mathrm{K}$-depleted rats. In contrast, however, there is an increase in the $\mathrm{NaCl}$ concentration of TAL fluid when equilibrium is achieved. We believe it is reasonable to assume that the rate of fall of the $\mathrm{NaCl}$ concentration-the rate constant $\tau$-reflects the uptake of $\mathrm{NaCl}$ across the luminal membrane. If this is correct, the similar rate constants in $\mathrm{K}$-depleted and normal rats suggest no impairment of the luminal transport step. Rather, the principal defect is most likely an enhanced rate of back-flux since normal equilibrium values cannot be achieved even with infinite time. We recognize that this formulation must remain speculative, particularly in view of the fact that medullary solute concentration in K-depletion must be reduced. However, in support of our view are results obtained with furosemide (an accepted inhibitor of carrier-mediated solute efflux), which produces the opposite effects on the rate constant and equilibrium values. Thus, Gutsche et al. $(7,17)$ has shown, using the same technique, that furosemide decreases the $\tau$ but does not change the $\mathrm{C}_{\mathrm{Eq}}$. Taken together, these data suggest that inhibition of net $\mathrm{NaCl}$ transport by the TAL in $\mathrm{K}$-depletion is due to an increase in the back-flux of $\mathrm{NaCl}$ into the lumen rather than to an impairment in $\mathrm{NaCl}$ uptake across the luminal membrane.

Whatever the mechanism of the impairment of net solute efflux by the TAL, our results should be viewed in the light of several recent studies. The proposed mechanism of sodium, chloride, and potassium transport by this segment has been recently reviewed by Burg (18). Briefly, in the cortical TAL of the rabbit, uptake of $\mathrm{Cl}$ across the luminal membrane requires cotransport of $\mathrm{Na}(19)$, is critically dependent on the presence of $K$ in the lumen $(20)$, and is inhibited by furosemide $(19,21)$.

Is it possible that insufficient $\mathrm{K}$ entered the perfused loops of Henle in K-depleted rats and that the reduction in luminal $\mathrm{K}$ was rate-limiting for $\mathrm{NaCl}$ transport? To address this issue, we measured $\mathrm{K}$ entry into loops perfused at $90 \mathrm{nl} / \mathrm{min}$ with zero $\mathrm{K}$ perfusate, and we measured $\mathrm{TAL} \mathrm{NaCl}$ transport in loops perfused with a K-containing perfusate $(5 \mathrm{mM})$. To determine whether luminal $\mathrm{K}$ concentration increased with a 5 $\mathrm{mM}$ perfusate, we also measured steady-state $\mathrm{K}$ concentration in loops perfused with $5 \mathrm{mM} \mathrm{K}$ at $90 \mathrm{nl} / \mathrm{min}$. Our results show that substantial amounts of $\mathrm{K}$ do enter the loop perfused with zero $\mathrm{K}$ in $\mathrm{K}$-depleted rats, although this amount of $\mathrm{K}$ was significantly less than that measured in the control rats. When loops were perfused with $5 \mathrm{mM} \mathrm{K}$, loop $\mathrm{K}$ concentration increased, and loop reabsorption of $\mathrm{K}$ exceeded that measured in controls, while $\mathrm{NaCl}$ transport by the TAL remained impaired. These results show that a reduction in luminal $\mathbf{K}$ delivery in $\mathrm{K}$-depletion is not rate-limiting for $\mathrm{NaCl}$ transport by the TAL and that acute restoration of luminal $\mathrm{K}$ delivery does not repair the transport defect in the TAL.

Since $\mathrm{NaCl}$ uptake across the luminal membrane appears to be normal in K-depletion, we must now consider whether changes in the rate of sodium efflux across the peritubular membrane could underlie the TAL defect. It is convenient to discuss this possibility under four headings: (a) quantitative changes in the peritubular pump; (b) ECF potassium concentration as a modulator of $\mathrm{NaCl}$ transport across the peritubular membrane; (c) the importance of repair of extracellular vs. intracellular potassium deficits on $\mathrm{NaCl}$ transport; and $(d)$ renal hemodynamic and structural influences.

(a) Quantitative changes in the peritubular pump. Once $\mathrm{NaCl}$ has crossed the luminal membrane, efflux across the peritubular membrane is thought to be driven by Na-K-ATPase, which is an integral part of this membrane. Although there are reports 
of reductions in mitochondrial enzyme activity and oxidative metabolism in outer medullary tissue from K-depleted rats (22, 23), Na-K-ATPase activity measured in the same tissue appears to be normal $(22,23)$. Thus a decrease in peritubular pump sites does not appear to account for the inhibition of TAL NaCl transport in K-depletion.

(b) ECF potassium concentration as a modulator of $\mathrm{NaCl}$ transport across the peritubular membrane. We suggest here that reduced ECF $[K]$ is rate-limiting for peritubular Na-K-ATPasemediated extrusion of sodium. It has been well established that the extrusion of $\mathrm{Na}$ from the cell by the Na-K-ATPase enzyme requires the obligatory transport of $\mathrm{K}$ into the cell. Inhibition of net $\mathrm{NaCl}$ transport caused by reduction of bath $\mathrm{K}$ concentration has been reported to occur in the isolated perfused TAL $(24,25)$. However, in these studies $\mathrm{K}$ was simultaneously removed from bath and lumen. The role, therefore, of reduced ECF $\mathrm{K}$ on $\mathrm{NaCl}$ transport by the TAL cannot be defined with certainty. More information exists concerning the effect of reduced bath $\mathrm{K}$ on net $\mathrm{NaCl}$ transport by the proximal tubule $(26,27)$, which is also an Na-K-ATPase dependent process. Evidence suggests that a reduction of bath $\mathrm{K}$ concentration below $2.5 \mathrm{mM}$ will inhibit net $\mathrm{NaCl}$ reabsorption in the isolated perfused proximal tubule of the rabbit (26). The Na-K-ATPase enzyme in isolated medullary TAL segments of the rabbit has been demonstrated to have maximal activity when bath [K] is $5 \mathrm{mM}$. Further increases in bath [K] up to $20 \mathrm{mM}$ were without effect. However, the enzyme is inhibited when bath $[\mathrm{K}]$ is reduced below $5 \mathrm{mM}(28)$. In the present studies we have shown a striking correlation between the impairment in TAL $\mathrm{NaCl}$ transport and plasma $\mathrm{K}$ concentration in our $\mathrm{K}$-depleted rats $(r=0.91)$. Using the equation of this line, it can be predicted that loop transport will be impaired if plasma $K$ is reduced below a value of $2.9 \mathrm{mM}$. Accordingly, the results of the present study are consistent with an effect of the reduction in ECF K caused by $\mathrm{K}$-depletion in down-regulating the Na-K-ATPase transport pump. However, we recognize that the quantitative contribution of such a regulatory process remains unclear.

(c) Importance of repair of extracellular vs. intracellular potassium deficits on $\mathrm{NaCl}$ transport. In the present investigation, administration of $2.5 \mathrm{mM}$ of $\mathrm{K}$ to $\mathrm{K}$-depleted rats completely reversed the inhibition of loop $\mathrm{NaCl}$ transport. In these rats, not only is plasma $\mathrm{K}$ concentration increased $(4.3 \mathrm{mM})$, but a large portion of the whole body intracellular deficit is restored (29). Therefore, the role of the increase in extracellular K concentration as opposed to intracellular stores in repairing the defect in loop $\mathrm{NaCl}$ transport is difficult to determine. Accordingly, we also studied diluting ability in $\mathrm{K}$-depleted rats that received intravenously a smaller amount of $K(0.75 \mathrm{mM})$ equivalent to only $30 \%$ of the deficit in total body $\mathrm{K}$ and sufficient to raise plasma $\mathrm{K}$ from 2.1 to $3.2 \mathrm{mM}$. These $\mathrm{K}$-infused rats were found to have normal $\mathrm{NaCl}$ transport by the TAL. In addition, TAL function was restored within $30 \mathrm{~min}$ after the $\mathrm{KCL}$ infusion was initiated, which suggests that major changes in synthesis of transport proteins were not required for the im- provement in $\mathrm{NaCl}$ transport. These results support the conclusion that a decrease in potassium concentration at the peritubular site (rather than a reduction in $\mathrm{K}$ stores) directly mediated the inhibition of $\mathrm{NaCl}$ transport by the TAL.

(d) Renal hemodynamic and structural influences. Notwithstanding the above discussion, the present studies cannot, of course, exclude the possibility of mediation of the defect by factors such as renal blood flow, which change in parallel with ECF $\mathrm{K}$ concentration. In K-depleted animals, repair of the potassium deficit by gavage allowed restoration of plasma $\mathrm{K}$ concentration at the same time that whole kidney GFR and TAL solute removal were normalized. In contrast, when K-depleted rats were infused with a smaller amount of potassium, the TAL defect was repaired without normalization of whole kidney GFR. Despite this, it is still possible that changes in regional renal blood flow, alteration in the products of the cyclo-oxygenase enzyme system, or angiotensin II in $\mathrm{K}$-depletion could exert effects on TAL transport, which the present studies have not addressed. In contrast, we believe it is clear that the rapid reversal of the defect in the presence of classic lesions of K-depletion $(9,10)$ indicates that structural changes in the TAL could not have played an important role.

In summary, we have undertaken a direct in vivo assessment of the diluting function of the TAL in K-depleted rats. A striking impairment in $\mathrm{NaCl}$ transport by the TAL is demonstrable by means of microstop-flow experiments in combination with in situ conductivity measurements of tubular fluid emerging from perfused loops of Henle. The degree of impairment is highly correlated with a decrease in plasma potassium concentration in $\mathrm{K}$-depleted rats, and is rapidly reversed by the acute systemic administration of potassium. Restoration of luminal K delivery alone in the K-depleted rat does not repair the defect in TAL$\mathrm{NaCl}$ transport. We propose that net $\mathrm{NaCl}$ reabsorption by the TAL is impaired in $\mathrm{K}$-depletion because the decrease in ECF $\mathrm{K}$ concentration is rate-limiting for peritubular Na-K-ATPase activity. We recognize that factors such as regional renal blood flow, local angiotensin II levels, and products of the cyclo-oxygenase enzyme system may play a role.

\section{Acknowledgments}

It is a pleasure to acknowledge the expert assistance of Mrs. L. A. Nash and Mrs. M. Iacovitti. Mrs. P. Morrissey expertly typed the manuscript. This work was funded in part by the Deutsche Forschungsgemeinschaft.

\section{References}

1. Whinnery, M. A., and R. T. Kunau, Jr. 1979. Effect of potassium deficiency on papillary plasma flow in the rat. Am. J. Physiol. 234:F226F231.

2. Mannitus, A., H. Levitin, D. Beck, and F. H. Epstein. 1960. On the mechanism of renal concentrating ability in potassium deficiencies. J. Clin. Invest. 39:684-692. 
3. Berl, T. 1980. Water metabolism in potassium depletion. Miner. Electrolyte Metab. 4:209-215.

4. Berl, T., S. L. Linas, G. A. Aisenbrey, and R. J. Anderson. 1977 On the mechanism of polyuria in potassium depletion. J. Clin. Invest. 60:620-625.

5. Eknoyan, G., M. Martinez-Maldonado, W. Suki, and Y. Ritchie. 1970. Renal diluting capacity in the hypokalemic rat. Am. J. Physiol. 219:933-937.

6. Gutsche, H. U., R. Muller-Suur, U. Hegel, and K. Hierholzer. 1980. Electrical conductivity of tubular fluid of the rat nephron. Pflüegers Arch. Eur. J. Physiol. 383:113-121.

7. Gutsche, H. U. 1980. Micro stop flow experiments: a new method for in vivo analysis of the function of the diluting segment. Contrib. Nephrol. 19:231-239.

8. Peterson, L. N., and F. S. Wright. 1977. The effect of sodium intake on renal potassium excretion. Am. J. Physiol. 233:F225-F234.

9. Levine, D. Z., T. Walker, L. A. Nash, and S. Raman. 1973. Effects of $\mathrm{KCl}$ infusions on proximal tubular function in normal and potassiumdepleted rats. Kidney Int. 4:318-325.

10. Ordonez, N. G., F. G. Toback, H. N. Aithal, and B. H. Spargo 1977. Zonal changes in renal structure and phospholipid metabolism during reversal of potassium depletion nephropathy. Lab. Invest. 36:3347.

11. E. W. Washburn, editor. 1929. International critical tables of numerical data, physics, chemistry, technology. McGraw-Hill Inc., New York and London. Vol. 6:230-261.

12. Morgan, T., and R. W. Berliner. 1969. A study by continuous microperfusion of water and electrolyte movements in the loop of Henle and distal tubule of the rat. Nephron. 6:388-405.

13. de Rouffignac, C., and F. Morel. 1969. Micropuncture study of water, electrolytes and urea movements along the loops of Henle in psammomys. J. Clin. Invest. 48:474-486.

14. Levine, D. Z., M. K. Byers, R. A. McLeod, J. A. Luisello, and S. Raman. 1977. Loop of Henle bicarbonate accumulation in vivo in the rat. J. Clin. Invest. 63:59-66.

15. Levine, D. Z., R. A. McLeod, and M. K. Byers. 1978. Flow correlation of loop of Henle potassium influx. Can. J. Physiol. Pharmacol. 56:533-535.

16. Jamison, R. L., F. B. Lacy, J. P. Pennell, and V. M. Sanjana. 1976. Potassium secretion by the descending limb or pars recta of the juxtamedullary nephron in vivo. Kidney Int. 9:323-332.
17. Gutsche, H. U., K. Mueller-Ott, R. Brunkhorst, and W. Niedermayer. 1983. Dose-related effects of furosemide, bumetanide, and piretanide on the thick ascending limb function in the rat. Can. $J$. Physiol. Pharmacol. 61:159-173.

18. Burg, M. B. 1982. Thick ascending limb of Henle's loop. Kidney Int. 22:454-464.

19. Greger, R. Chloride reabsorption in the rabbit cortical thick ascending limb of the loop of Henle. 1981. Pflüegers Arch. Eur. J. Physiol. 390:38-43.

20. Greger, R., and E. Schlatter. 1981. Presence of luminal $\mathrm{K}^{+}$, a prerequisite for active $\mathrm{NaCl}$ transport in the cortical thick ascending limb of Henle's loop of rabbit kidney. Pflüegers Arch. Eur. J. Physiol. 392:92-94.

21. Burg, M. B., L. Stoner, J. Cardinal, and N. Green. 1973. Furosemide effect on isolated perfused tubules. Am. J. Physiol. 225:119124.

22. Kannegiesser, H., and J. B. Lee. 1971. Role of outer renal medullary metabolism in the concentrating defect of $\mathrm{K}$ depletion. Am. J. Physiol. 220:1701-1707.

23. Weiner, M. W., L. A. Sauer, J. Torretti, and F. H. Epstein. 1971. Renal mitochondrial enzymes in potassium depletion. Am. J. Physiol. 221:613-617.

24. Burg, M. B., and J. E. Bourdeau. 1978. Function of the thick ascending limb of Henle's loop. In New Aspects of Renal Function. H. G. Vogel and K. J. Ullrich, editors. Exerpta Medica, Amsterdam. 91-102.

25. Greger, R. 1981. Cation selectivity of the isolated perfused cortical thick ascending limb of Henle's loop in the rabbit kidney. Pflüegers Arch. Eur. J. Physiol. 390:30-37.

26. Cardinal, J., and D. Duchesneau. 1978. Effect of potassium on proximal tubular function. Am. J. Physiol. 234:F381-F385.

27. Burg, M. B., and N. Green. 1976. Role of monovalent ions in the reabsorption of fluid by isolated perfused proximal renal tubules of the rabbit. Kidney Int. 10:221-228.

28. Doucet, A., A. I. Katz, and F. Morel. 1979. Determination of Na-K-ATPase activity in single segments of the mammalian nephron. Am. J. Physiol. 237:F105-F113.

29. Linas, S., L. N. Peterson, R. J. Anderson, G. A. Aisenbrey, F. R. Simon, and T. Berl. 1979. Mechanism of renal potassium conservation in the rat. Kidney Int. 15:601-611. 